\begin{tabular}{|c|c|}
\hline \&ut & $\begin{array}{l}\text { AUFKLÄRUNG, João Pessoa, v.3, n.2, Jul-Dez., 2016, p.61-72 } \\
\text { DOI: http://dx.doi.org/10.18012/arf.2016.30950 } \\
\text { Recebido: } 25 / 08 / 2016 \mid \text { Aceito: } 15 / 09 / 2016 \\
\text { Licença: Creative Commons 4.0 International (CC BY 4.0) }\end{array}$ \\
\hline
\end{tabular}

\title{
LA CIUDADANÍA COMO LO PROPRIAMENTE HUMANO: DIGRESIONES ENTRE LA NATURALEZA INDENTITARIA ILUSTRADA Y UNA POLÍTICA DE LA DIFERENÇA ANIMAL
}

\author{
[CITIZENSHIP AS WHAT'S PROPERLY HUMAN: DIGRESSIONS BETWEEN ILLUSTRATED HUMAN IDENTITY \\ AND POLITICS OF ANIMAL DIFFERENCE]
}

Pedro E. Moscoso Flores *

Nicolás Fuster Sánchez **

\begin{abstract}
RESUMEN: El presente intenta hacer explícita una tensión que circula dentro del pensamiento moderno, en relación con la condición del hombre como ciudadano y de sus implicancias respecto de los modos en que se puede pensar la política. A partir de un análisis del pensamiento kantiano, específicamente el referido al problema de la apropiación por medio de la razón, se busca establecer un impacto diferencial con el pensamiento de Nietzsche y Benjamin, entendiendo que ambos autores buscan una salida al problema impuesto por la ciudadanía moderna a partir de una reconexión del hombre con su condición animal, subvirtiendo el dualismo entre naturaleza y cultura.
\end{abstract}

Palabras Clave: Ciudadano - Modernidad Condición animal - Naturaleza - Cultura
ABSTRACT: This text attempts to make explicit a flowing tension in modern thought, regarding the condition of men as a citizens and its implications concerning the ways in which politics are thought. From the analysis of Kantian thought, specifically referred to the problem of ownership by means of reason, the objective is to establish a differential impact with the thought of Nietzsche and Benjamin, understanding that both authors seek a solution to the problem imposed by modern citizen by instating a reconnection between men and their animal condition, subverting the dualism between nature and culture.

KEYwORDS: Citizen - Enlightenment - Animal condition - Nature - Culture

\section{INTRODUCCIÓN}

Z1 objetivo del presente trabajo es desarrollar una discusión sobre el lugar que le compete a la noción de ciudadanía. En esta línea, intentaremos demostrar que dicha figura, representada de manera particular a partir de la modernidad ilustrada, se convierte en una categoría discursiva necesaria para la construcción de un proyecto centrado en ideales republicanos, tal como aparecen en el pensamiento político de Kant. Para probar dicha tesis recurriremos al pensamiento de Nietzsche y Benjamin, como medio de contraste que nos permita visibilizar la lógica del fundamento político ilustrado como un ejercicio de violenta desarticulación de una naturaleza animal, preontológica, siendo ésta reemplazada por una forma de organización, un orden cuyo efecto es la emergencia del individuo autónomo, ciudadano voluntarioso y racionalmente libre. Terminaremos discutiendo la posibilidad de pensar la condición ciudadana como un proceso de subjetivación enclavado en un ejercicio de apropiación

*Dr.en Filosofia.Universidad Adolfo Ibáñez,Chile.m@aito: pedro.moscoso@uai.cl. **Dr.en Filosofia.Universidad de Valparaiso,Chile.m@ilto: nicolas.fuster@uv.cl 
de una serie de marcas identitarias que permiten, a la postre, la materialización fenomenológica del ideal ilustrado a partir de un ejercicio de con-formidad entre una naturaleza racional -desnaturalizante- del hombre y su dis-posición hacia la comunidad sostenida por el ideal de humanidad.

La figura del ciudadano - citoyen-, se puede entender como una configuración

62 taxonómica que cobra un ángulo particular dentro del pensamiento racional que inaugura la modernidad. La conformación de dicha categoría, en clara analogía con el sujeto de derecho contemporáneo, constituye algo así como un engranaje en la producción de un modo de subjetivación propio de una racionalidad gubernamental desde el que operan una serie de mecanismos de poder, específicamente a través de la puesta en obra de una configuración identitaria particular que tiende a una sofisticación progresiva de conductas y referentes normativos necesarios para encajar dentro de dicha categoría civil.

Lo señalado se vislumbra en el problema que el filósofo Kant inauguró respecto a la relación entre la moral trascendental y su correlato fáctico, estableciendo así las condiciones para la constitución y fundamentación del derecho político, lo que en definitiva deviene en la posibilidad de pensar una experiencia práctica universal fundada en lógicas duales de inclusión/exclusión. El resultado de dichas lógicas de adjetivación de la ciudadanía sería la producción de una serie de límites de acción moral posibles - públicos/privados- para el hombre, a partir de la puesta en circulación de determinados espacios portadores de significado (Agamben, 2005), re-creando de este modo un espacio social-moral universalizante, es decir, una comunidad política proyectada universal e infinitamente hacia una concepción de futuro guiada por el telos ilustrado que depositará su posibilidad de materialización en la figura del hombre racional devenido ciudadano. Así entendido, el hombre vinculado al estado de naturaleza ${ }^{1}$ quedaría por siempre tachado, por cuanto no habría sido incapaz de insertarse dentro de los límites del contrato social.

\section{El GESTO KANTIANO: LA ILUSTRACIÓN DE LA NATURALEZA}

El concepto de ciudadanía puede ser considerado como uno que comporta, en sí mismo, una determinada ambigüedad estructural. Éste puede incluir desde la pertenencia a una determinada comunidad política, hasta la capacidad de participación política en un régimen democrático desde el que se entendería al ciudadano en un sentido de oposición al súbdito. Desde otro registro, la ciudadanía podría ser explicada tanto desde una visión descriptiva como una asociativa. De acuerdo con la primera, la lógica imperante sería la de establecer un cierto tipo de individuos que, por su condición, pudiesen ejercer cierto tipo de derechos. La segunda alude a la idea de que nos constituimos a partir de nuestra participación compartida en una sociedad, es decir, refiere a los modos en que nos vinculamos con la comunidad política a la que pertenecemos (Storey, 2011).

Un elemento definitorio dentro de la definición de dicha condición ${ }^{2}$, a partir del siglo XVII, es la inclusión de los derechos humanos dotados de carácter universal ${ }^{3}$, lo que culminaría con el reconocimiento de los derechos de libertad individual (Ruíz, 2008). En esto, sin duda, el pensamiento kantiano ha tenido una gran influencia por cuanto integraría la noción descriptiva del individuo como ser responsable de sus acciones: "Una persona es el sujeto cuyas acciones son susceptibles de imputación. La personalidad moral, pues, no es más que la libertad de un ser racional sometido a leyes morales" (Kant, 2005, 32). Pero al mismo tiempo operaría de manera asociativa, ya que el principio de autonomía implicaría la consideración de la humanidad, en tanto voluntad general, como principio universal de la razón práctica basado en la máxima de 
la libertad.

Vislumbramos en del pensamiento del filósofo prusiano dos grandes ámbitos desde donde abordar el problema en cuestión. El primero de ellos dice relación con la vinculación entre el pensamiento moral y el jurídico, es decir, el problema del ciudadano como sujeto de derecho dentro de los límites que impone la razón. El segundo tiene que ver con un abordaje de la naturaleza humana que Kant problematiza en dos niveles: por una parte, cuestionando la naturaleza como un estado previo que el hombre debe superar en el camino hacia un estado de ciudadanía, tal y como lo planteara Hobbes ${ }^{4}$. Por otro, la inclusión del problema de la especie, a propósito de la ciudadanía cosmopolita, en que Kant parece resituar el problema de la naturaleza al articularlo con el fin moral del hombre. De este modo el filósofo prusiano sienta las bases de un modelo ético-político con cualidad universal, a partir de un ideal de humanidad que servirá, al menos como referente, para todos los proyectos posteriores en el campo de la filosofía política, moral y del derecho.

Volviendo al problema que nos convoca, nos parece pertinente comenzar con la definición de ciudadano que nos lega en su Metafísica de las Costumbres: "Los miembros de una sociedad semejante (societas civilis) -es decir, de un Estado-, unidos con vistas a la legislación, se llaman ciudadanos (cives) y sus atributos jurídicos, inseparables de su esencia (como tal), son los siguientes: la libertad legal de no obedecer a ninguna otra ley más que a aquella a la que ha dado su consentimiento; la igualdad civil, es decir, no reconocer ningún superior en el pueblo, sólo a aquel al que tiene la capacidad moral de obligar jurídicamente del mismo modo que éste puede obligarle a él; en tercer lugar, el atributo de la independencia civil, es decir, no agradecer su propia existencia y conservación al arbitrio de otro en el pueblo, sino a sus propios derechos y facultades como miembro de la comunidad, por consiguiente, la personalidad civil que consiste en no poder ser representado por ningún otro en los asuntos jurídicos (Kant, 2005, 143-144).

A simple vista la comprensión de la ciudadanía, como constructo sustentado en una determinación jurídica, no coincide plenamente con la disposición moral del ser humano planteada por $\mathrm{Kant}^{5}$, ya que si bien es cierto que esta última se aplica a todos por igual parece no ocurrir lo mismo con la comprensión del hombre en tanto ciudadano. Lo anterior queda constatado en su escrito Teoría y Práctica, en donde el filósofo, al referirse a la constitución civil cuyo fin primordial e incondicionado debe ser a unión entre las personas, señala que sus tres elementos esenciales son, respectivamente: la libertad de cada uno de sus miembros (en tanto hombres); la igualdad entre ellos (en tanto súbditos); y, por último, la independencia de cada miembro de una comunidad (en tanto ciudadanos). Es sobre este último punto problemático que apuntará una distinción entre ciudadanos y co-protegidos (Kant, 2004).

Lo anterior deja entrever que el tercer principio es exclusivo de aquellos quienes puedan adquirir independencia, en este caso referida al patrimonio económico. Esto se grafica explícitamente a partir de dos postulados: primero, al establecer que la igualdad política no se hace incompatible con la desigualdad económica; segundo, en el gesto de exclusión que Kant postula en relación con los niños, mujeres y aquellos hombres que se encuentran en una posición de dependencia económica, quiénes no tendrían acceso al elemento determinante de una práctica activa de ciudadanía, a saber, el derecho a sufragio (Kant, 2004).

A partir de lo anterior surge una suerte de graduación de la ciudadanía, en la que todos los seres racionales dependientes serían considerados como ciudadanos pasivos, mientras que aquellos que posean independencia económica podrán ser considerados ciudadanos activos y, por ende, tendrán derecho a circular de manera vinculante con las estructuras de poder imperantes ${ }^{6}$. Por lo tanto, podríamos pensar que el tema de la 
posesión juega un rol fundamental; posesión, que como bien señala Kant, debe ser siempre respecto de un elemento externo (un bien, un territorio o la propia labor como mercancía de intercambio $)^{7}$. Dicha condición vendría a instalar, a simple vista, una fractura entre el imperativo categórico (incondicional, a priori) y la relación causal impuesta por la experiencia ciudadanía plena, es decir, de carácter fenomenológico.

Sin embargo, al volver la atención sobre la noción de propiedad que el propio Kant plantea, es decir, lo que determina lo propio en el caso de la ciudadanía, vemos que la determinación de la propiedad privada se encontraría condicionada por los principios a priori de la razón práctica. De tal modo que al referirse al fundamento jurídico de la posesión, Kant nos muestra de inmediato que éste no dependería directamente de la experiencia ni de sus dimensiones espacio-temporales: "La definición nominal, es decir, aquella que basta para distinguir un objeto de los demás y resulta de una exposición completa y determinada del concepto, sería la siguiente: lo mío exterior es aquello fuera de mí, cuyo uso discrecional no puede impedírseme sin lesionarme (sin perjudicar a mi libertad, que puede coexistir con la libertad de cualquier otro según una ley universal). -Pero la definición real de este concepto, es decir, aquella que basta también para su deducción (para el conocimiento de la posibilidad del objeto), dice así: lo mío exterior es aquello cuyo uso no puede estorbárseme sin lesionarme, aún cuando yo no esté en posesión de ello (no sea tenedor del objeto)" (Kant, 2005, 60).

De modo que la posesión, como principio, sería anterior a toda posesión empírica y determinaría a esta última. En otras palabras, el objeto, en la medida que le pertenece al sujeto a partir de su creación representacional dentro de la relación hombre-mundo, sería una relación intelectual guiada por los principios del entendimiento. Desde esta perspectiva, a pesar que la condición de ciudadanopropietario parece jugarse a partir de la acción de aprehensión del objeto exterior (possesio phaenomenon), lo importante sería la apropiación (possesio noumenon), como acto de voluntad universal por el que se obliga a todos a concordar con el propio arbitrio.

Dicha acción de apropiación tendría una determinación sobre el «sí mismo» del ciudadano, es decir, emergería en la relación misma entre este y el objeto. En tal caso, el objeto sería entendido como cosa en sí, supeditado al concepto racional puro práctico del arbitrio bajo las leyes de libertad. Es más, si la determinación de la ciudadanía plena pasa efectivamente por dicho principio jurídico, parece inevitable que exista una predeterminación moral en la conformación de lo jurídico, a saber, como fondo normativo sobre el que éste se puede pensar y fundar. Por ende, para poder estar en posesión de algo exterior a mí es necesario que opere bajo las leyes de coexistencia -de no perjudicar la libertad otro-, propias de la ley universal.

De este modo consideramos que la posesión del objeto, en tanto política del reconocimiento entre lo propio y lo ajeno, operaría como una suerte de borde identitario, del sujeto ciudadano, en relación con el otro. En otras palabras, la posesión contiene un fondo que va más allá de la mera relación al objeto, que evidentemente no puede ser imputado moralmente, sino que impondría un imperativo de reconocimiento del otro en tanto posesión común. De modo que lo importante no es sólo que el yo lo posea, sino que el otro reconozca dicha posesión para que se cumpla el principio universal de libertad.

Existe en lo anterior alguna afinidad con la noción de ciudadanía que plantea Kojève a propósito de su lectura hegeliana: aquella en la que se entiende al ciudadano como quién reconoce a aquel que pide ser reconocido (Kojève, 1980; Esposito, 2009). Sin embargo, en este caso la referencia directa al objeto de la posesión alude a una voluntad omnilateral que se encuentra ya inscrita dentro del sujeto, es decir, de una adquisición intelectual que involucra la voluntad de todos unificada a priori y que sólo 
es posible dentro de un estado civil. En esto, creemos, subsistiría una suerte de dualismo metafísico plasmado en el contrato original y predefinido por la disposición universal de la ley, lo que daría cuenta del acceso a un particular orden simbólico por parte de la razón, produciendo determinados espacios portadores de significado. Y no sólo eso, sino que vendría a imponer determinadas condiciones de acción a priori para ser sujeto reconocido jurídicamente, lo que podría ser leído como una violencia entre el saber, en que esta categoría se constituye, y su relación con los objetos a los que remite.

En relación con el segundo punto problemático, a saber, el de la vinculación de la naturaleza con la noción de ciudadanía, creemos necesario situar el carácter diferencial del hombre, en tanto ser racionalmente finito, respecto al resto de los seres vivos. En tal sentido, nos parece particularmente iluminadora la posición que Kant asume en torno al carácter definitorio del hombre a propósito de su Antropología: "El que el ser humano pueda tener al Yo entre sus representaciones, lo eleva infinitamente por sobre otros seres vivientes sobre la tierra. Gracias a eso, él es una persona, y, debido a la unidad de conciencia, [es] una y la misma persona a través de todas las mudanzas que pudiera ocurrirle; es decir, un ser que, por su rango y dignidad, es enteramente diferente de las cosas (como lo son las bestias privadas de razón, de las que puede disponer a capricho" (Kant, 2009, 23).

Por tanto, lo que vendría a poner al hombre en una posición de superioridad respecto al resto de las criaturas sería, justamente, su capacidad de representarse un yo entendido como unidad de conciencia. Lo anterior es determinante al vincular dicha capacidad con su fundamento práctico, a saber, el deber de tener control sobre sus propias inclinaciones (animus sui compos), haciendo frente de esta forma a los mecanismos imaginativos, propios de la razón, que tienden a representarse las cosas de manera contraria a su fin ${ }^{8}$. De este modo, "[...] se instaura la apostasía de las inclinaciones naturales y el nacimiento de la conciencia, rompiendo el orden de la naturaleza e instaurando la libertad y el ámbito de la moralidad imperfecta. Aquí está el origen del mal. Ha nacido el arbitrio humano frente al animal" (Cit. en Ponce, 1999, 117-142). Al respecto Kant agrega que: “[...] él tiene un carácter que él mismo se procura, al tener la facultad de perfeccionarse de conformidad con los fines que él mismo adopta; mediante lo cual él, como animal dotado de la facultad de la razón (animal rationabile) puede hacer de sí mismo un animal racional (animal rationale) [...]" (Kant, 2005, 328).

El parágrafo citado hace referencia a una disposición que la naturaleza le otorga al ser humano, una suerte de naturaleza flexible que le da la posibilidad de determinar su propio destino. En otras palabras, una disposición moral del ánimo que le permitiría al sí mismo darse un destino y un carácter con independencia de los mecanismos naturales, paradójicamente, donados por la misma naturaleza. Entendemos que lo que se inaugura a partir de dicha diferenciación entre el hombre y la naturaleza es justamente una economía particular entre lo animal y lo humano basada en una distinción que deviene exclusión. Esto podría leerse en clave de un Orden que establece una particular manera de representarse los órdenes de estas relaciones duales; es decir, lo que sostiene la identidad del hombre como una que se produce en su posibilidad de reconocerse -en alusión a la autoconciencia-, de modo similar al planteamiento de Linneo, según el que el hombre es un animal que debe reconocerse humano para serlo (Agamben, 2005).

De modo que el reconocimiento de lo humano se sostiene en base a un estado diferencial respecto de la animalidad: el hombre se definirá en su relación de contigüidad o distancia con éste último, más nunca podrá estar al mismo nivel que el animal por cuanto posee la capacidad de evaluar moralmente ${ }^{9}$. Dicho de otro modo, lo que separa a la especie humana del resto de las especies no humanas es la capacidad de 
posicionarse activamente respecto a su fin último, a diferencia de los animales que se conformarían con los placeres sensibles que pueden alcanzar en el estado de naturaleza. Esto presupone un quiebre radical entre lo racional y lo sensible, en que el primero impone un poder que permitirá encauzar la animalidad hacia su destino último. Así se asegura una modalidad de gobierno basada en la autonomía del ciudadano, considerando que lo que está en juego en el interior del sujeto racional no es más que su propia voluntad puesta en una relación de voluntad común con los otros decididores.

Dicho planteamiento revelaría una suerte de satanización de los impulsos a partir de una concepción descarnada de la naturaleza humana, debiendo en todo momento ejercer una función reguladora sobre ellos. Desde este punto de vista podría comprenderse una operación de división de la vida que subsiste dentro de lo humano -a partir de una presunción ontológica racional interiorizante- ; una en que el hombre civilizado se erige como una identidad residual producida gracias a una desconexión entre lo biológico y lo social (Agamben, 2005).

Este punto de vista nos permite conjugar una interpretación de la especie humana kantiana como espacio de coalición que debe buscar la regulación entre dos sentidos contrapuestos: por un lado, la posibilidad de una convivencia pacífica a partir de la suscripción al ideario civilizatorio ilustrado y, por otro, un antagonismo o mala tendencia proporcionada por la naturaleza; en otras palabras, el bien conocido proceso de integración de la concordia con la discordia que opera como principio regulativo: la insociable sociabilidad (Kant, 2004). Esto será lo único que asegure el progreso en tanto fin final -generacional- de la especie humana, pensable sólo dentro de un proyecto de sociedad civil universal. Es por esto que el hombre debe abandonar el instinto que lo llama a abandonarse pasivamente a los placeres y emplearse activamente hacia la búsqueda de la humanidad haciendo uso de su razón.

Lo curioso es que este gesto se hace posible gracias a un influjo que la misma naturaleza proporciona, cobrando esta última una segunda significación. Ya no basta con aludir a un estado de naturaleza primitivo del que se hace preciso salir, sino es necesario considerarla como aquello que impone una fuerza suprema coludida con el ideal de la razón práctica: una Providencia que se impone sobre los deseos individuales, forzando a los hombres a tomar un camino que no tomarían por sí mismos. Pareciera existir, entonces, una disposición moral-racional subyacente en la salida del estado de naturaleza y su tránsito hacia el estado civil, posibilitada por la fragmentación categorial entre ambos estados que a su vez se encuentran anclados en una división -natural- de la naturaleza. En este esquema, la ciudadanía cosmopolita emerge como noción que cobra forma en base a una reconstitución de la ciudadanía dentro de un proyecto de carácter eminentemente teleológico, a saber, uno en que el hombre fenoménico comienza a subordinarse al hombre suprasensible. Dicho gesto puede ser entendido como la condición de posibilidad para la emergencia del ciudadano desde una perspectiva antropocéntrica.

Por ende, entendemos la figura del ciudadano cosmopolita como el resultado de la integración entre el sujeto moral de la razón práctica y el sujeto de derecho dentro de la sociedad civil. Sería un hombre que pertenece al dominio universal, pero a su vez concreto, guiado por una serie de reglas jurídicas que coinciden con la ley moral. Esto marca el punto en que el hombre -en tanto yo fenoménico- pierde relevancia, siendo reemplazado por el ciudadano como sujeto de derechos y deberes -en tanto único sujeto representable dentro del mundo moral-.

Dicho de otro modo, sería el espacio de convergencia entre el sujeto (que ejerce su soberanía en tanto pensante) y la humanidad como principio activo fundado en la idea de cultivarse, civilizarse y moralizarse: "el hombre, en la Antropología, no es ni homo natura, ni sujeto puro de libertad, sino que es tomado en las síntesis ya operadas de su ligazón con el mundo (...) sólo a partir del hombre puede pensarse el absoluto" 
(Kant, 2009, 69-88). Dicha humanidad podría ser leída como una segunda naturaleza, suprasensible (archetypica), alejada de toda temporalidad, desde donde es posible ordenar al ser en la medida que constituye una condición limitativa para todos los fines subjetivos (Ponce, 1999).

\section{A PROPÓSITO DE LA «DIFERENCIA ANIMAL»: BENJAMIN Y NiETZSCHE}

Tal y como hemos venido señalando hasta ahora, entendemos que la constitución del ciudadano en su naturaleza ilustrada se enmarca dentro de un momento cumbre de la historia occidental que, según Arnoldo Siperman, sería: "el de su sistema de filosofía crítica, la de los principios a priori, la de la moralidad fundada en la libertad y en el consentimiento, la que expulsa el misterio y rechaza la obediencia como su fundamento. La libertad, como atributo del sujeto autónomo y presupuesto de la vida moral, está en el corazón de la concepción kantiana. Es la idea de la moral como autogobierno, que supone el efecto obligatorio de las normas que regulan la vida en sociedad como consecuencia de la autonomía que se reconoce en el sujeto para autoimponerse, en la escala social, las leyes que lo gobiernan (...) la autonomía supone obrar según una ley universal que reconocemos y aceptamos como dictada por la razón. En otras palabras, la libertad consiste en darse a sí mismo la ley moral (Siperman, 2008, 188-189).

Esta ley universal dictada por la razón se mostrará, en palabras de Walter Benjamin, como la esfera de la lengua hecha, charlatanería del derecho que se apropia de las cosas y modela al buen ciudadano. Haciendo que el hombre pierda "en experiencia aquello que gana haciendo uso práctico de la razón" (Galende, 2009, 39). Así, Benjamin plantea una crítica a la noción de hombre, configurado por el derecho a partir de la figura de la culpa, y del derecho, en cuanto dispositivo de formación de la realidad y, por ende, del ciudadano. Sólo habría historia cuando existe un orden ético configurado, y cuando su configuración es un efecto de la producción de la vida como una culpa (Galende, 2009, 18).

Desde esta perspectiva, se busca poner en evidencia los efectos del derecho que cae "con todas sus fuerzas sobre cualquier vida que tienda a ir más allá de su horizonte natural de vida biológica (...)", logrando que el hombre total, "(...) cuesco profundamente vivo en la cáscara muerta de la existencia humana (...)", quede "(...) aplastado contra la pared del destino". En este sentido, en Benjamin se observa "(...) una contraposición entre la condición impropiamente temporal del plexo de culpa obrado por el destino, y un tiempo que se diferencia por su tipo y por su medida: el tiempo de la redención". Como señala Galende, "Benjamin sitúa aquí el tiempo del destino como un tiempo impropio en el sentido de que es parasitario y depende del tiempo propio de un tipo de vida superior, es decir, del tiempo de una vida que rehúye de esta mera vida natural y limitada a su propia existencia biológica" (2009, 11-20). Para Benjamin esta mera vida sería la vida tal como se haya dispuesta, tal como la conocemos y padecemos en su forma habitual. Esta naturalización de lo cotidiano estaría configurada o destinada por la esfera del derecho o de la ley universal. Es decir, podríamos pensar que para Benjamin el derecho destina.

Benjamin, lector de Nietzsche, logró al igual que el filósofo de la genealogía denunciar el agotamiento de estas categorías políticas, para provocar, de este modo, la abertura de un nuevo horizonte de sentido (Esposito 2006). Por esto se entiende que Nietzsche, tal como explica Patxi Lanceros, "abre un campo inmenso de experiencia y pensamiento al apalabrar simultáneamente la muerte de Dios, el eterno retorno y la necesidad de 'superar al hombre'. Parece tratarse de un extraño capricho por el cual el pensamiento, liberado de las ataduras de la antropología y la dialéctica, salta los límites 
de la razón (...) al transgredir los límites de la experiencia posible -dentro de los cuales se había refugiado la filosofía a partir de la primera crítica kantiana- la propia filosofía queda seriamente comprometida $\mathrm{y}$, con ella, el sujeto vinculado a la mencionada 'experiencia posible' y al lenguaje filosófico-discursivo" (Lanceros, 1996, 67-68).

Es por ello que la crítica de Benjamin al modelo kantiano -en tanto comprensión del conocimiento como atemporal que se aparta de la condición fugaz que subyace a la experiencia- radicaría, según Galende, en una concepción del conocimiento que se funda en el supuesto de que hay algo así como "un objeto para un sujeto", y en la pretensión ingenua de Kant “(...) por establecer una relación objetiva entre la conciencia empírica y el concepto objetivo de experiencia". Para Benjamin, la experiencia se da siempre en ausencia del sujeto: "Sujeto, en realidad, es el nombre para algo que siempre llega tarde a la experiencia, así como es experiencia el nombre para aquello que irrumpe en el páramo del ser, antes o después que existencia y existente se anuden en el lecho de la subjetividad" (Galende, 2009, 37-40).

En este sentido, para Benjamin "la tarea de la futura teoría del conocimiento es encontrar la esfera de total neutralidad en relación con los conceptos de objeto y sujeto". Es decir, "Buscar la esfera autónoma propia del conocimiento en que este concepto ya no se refiera en modo alguno a la relación entre dos entidades metafísicas" (Galende, 2009, 40). En Benjamin se esboza, de este modo, una suerte de empresa que buscará la articulación de un conocimiento des-subjetivado.

En la misma línea de Benjamin, creemos que el pensamiento de Nietzsche ofrece una salida alternativa al problema del pacto tácito que permite esbozar la figura del ciudadano cosmopolita moderno, en tanto buscaría recomponer aquella fractura entre hombre/animal consolidada por el pensamiento ilustrado, a saber, aquella que habría legitimado la producción de esta identidad civil a partir de la prescripción de una ejercicio de distinción con tintes teleológicos. El intento de Nietzsche pasaría por restituir la continuidad del hombre con el animal, no desde una perspectiva evolucionista ni materialista-mecánica, sino en una suerte de conexión particular en que la cultura (entendida como creación) se instituye como bisagra del hombre-animal.

Sabemos que el pensamiento nietzscheano revela la fragilidad del andamiaje de la filosofía política moderna, al dejar en evidencia la inexistencia de un "sujeto individual de voluntad y de conocimiento sustraído y anterior a las formas de poder que lo estructuran" (Esposito, 2006, 129). Nietzsche reconoce el poder portador de la vida misma, entendiendo que su dimensión política no se relaciona con algo que vive con anterioridad, con el destino, con la ley que sujeta, fomenta y guía una vida biológica, sino más bien con una voluntad de poder: una vida que "(...) no conoce modos de ser distintos al de una continua potenciación" (Nietzsche, 2007, 129-130). Es decir, existiría un tipo de vida resistente y refractaria a cualquier forma de captura política (ciudadanía, identidad), a la categorización política. En esta dirección, la resistencia sería un elemento central de la vida que lucha por no ser definida: "Las sublevaciones pertenecen a la historia. Pero, en cierto modo, se le escapan. El movimiento mediante el cual un solo hombre, un grupo, una minoría o un pueblo entero dice: «no obedezco más», y arroja a la cara de un poder que estima injusto el riesgo de su vida - tal movimiento me parece irreductible - . Y ello porque ningún poder es capaz de tornarlo absolutamente imposible: Varsovia siempre tendrá su gueto sublevado y sus cloacas pobladas de insurgentes. Y también porque el hombre que se alza carece finalmente de explicación; hace falta un desgarramiento que interrumpa el hilo de la historia, y sus largas cadenas de razones, para que un hombre pueda «realmente» preferir el riesgo de la muerte a la certeza de tener que obedecer" (Foucault, 2010, 861).

Al respecto, Patxi Lanceros señala: "Todo ejercicio de definición consiste en la implementación de límites y fronteras, en el establecimiento de un territorio habitable y en la correlativa heterodesignación de un entorno inhóspito u hostil (que opera, con la 
venida de Derrida, como exterior constitutivo del interior constituyente). La definición, aunque se ejerza en el ámbito del discurso -o precisamente por ello- es un ejercicio de poder, un acto político (en sentido amplio); aunque sólo sea por el hecho de que de-fine o de-limita el que puede hacerlo, el que tiene poder para ello y ocupa una determinada posición: que tiende a imponerse. Los límites y fronteras producidos por la definición suelen, además, generar aranceles y peajes" (Lanceros, 2005, 114).

En definitiva, la apropiación de la vida por parte de la política -lo que para Foucault estaría dado por la relación entre la disciplina, en tanto tecnología de control sobre la vida del cuerpo, y la biopolítica, entendida como tecnología política de control de la vida biológica de la especie-, generaría no sólo sometimientos, sino también resistencias o contra-conductas que liberarían al humano del dominio de otros y que lo empujarían a buscar y experimentar nuevas formas de vivir la propia vida -lo que para Foucault sería el cuidado de sí-.

Es en relación con estos mecanismos de resistencia que el historiador francés enuncia por Tecnologías del Yo "(...) aquellas que permiten a los individuos efectuar (...) cierto número de operaciones sobre su cuerpo y su alma, pensamientos, conducta, o cualquier forma de ser, obteniendo así una transformación de sí mismos con el fin de alcanzar cierto estado de felicidad, pureza, sabiduría o inmortalidad" (Foucault, 1990, 48).

Volviendo al filósofo Nietzsche, y retomando el análisis de Lemm, entendemos que la resistencia al poder, “(...) contrarresta a los procesos de individualización, la constitución del sujeto en y a través de su transformación en especie, por medio del cultivo y un cuidado de sí que redefine el estatus de la animalidad del ser humano" (Lemm, 2010, 351). Es por ello que en Nietzsche a vida animal desempeñaría un rol vital en la autocomprensión del ser humano, en su política y su cultura (Lemm, 2010b, 365), ya que vincularía al humano con una función de creatividad como fuerza superior contraria a toda voluntad de dominación (negación) de la vida.

Nietzsche realiza una distinción radical entre civilización y cultura, como dos formas antagónicas de politizar la vida animal. Mientras la civilización se articula como un dispositivo-político ilustrado-humanista que tiene como fin la domesticación de la animalidad del ser humano (la libertad del humano radica en su capacidad de emanciparse de su animalidad), la cultura, "implica una apertura a la animalidad orientada a la pluralización de formas de vida intrínsecamente singulares, formas de vida que se resisten a ser subsumidas bajo una totalidad (...) Mientras la política de una civilización es producir una sociedad normalizada a través de los medios violentos de la domesticación y cría del animal, el objetivo de una política de la cultura es el de cultivar formas de sociabilidad y comunidad a partir de la praxis de autorresponsabilidad individual" (Lemm, 2010b, 354-355).

Sin embargo, la verdadera capacidad de la cultura para potenciar una pluralización de formas de vida singulares radicaría en su imbricación con la creatividad, con el arte. Es por esto que para Nietzsche, "el problema de una cultura se comprende bien con poca frecuencia. Su objetivo no es la mayor felicidad posible de un pueblo, tampoco el desarrollo sin trabas de todas sus aptitudes, sino que se muestra en la justa proporción de ese desarrollo. Su fin apunta por encima de la felicidad terrestre: la creación de grandes obras es su fin" (Nietzsche, 2007, 169-170).

En este sentido, el olvido animal -propio de la animalidad-, incrementaría la creatividad del ser humano definiendo de esta manera la creatividad del genio popular, cuya consecuencia es, para Nietzsche, una cultura. Es decir, el "dominio del arte sobre la vida". Es por ello que "el grado de su calidad depende en primer lugar del grado de este dominio, y en segundo lugar del valor del arte mismo" (Nietzsche, 2007, 168-173). Este dominio que ejercería el arte sobre la vida posibilitaría, para el filósofo: "la transformación de la historia en un arte de la interpretación (...) provocando una nueva 
conciencia y autoconciencia en el ser humano que pueda guiarlo, en primer lugar, a autoafirmarse como animal, como ser histórico y tendiente al olvido; y, en segundo lugar, para que identifique en su memoria una fuerza creadora de vida. La perspectiva del olvido animal revela que la memoria es una fuerza artística (Kunsttrieb) y que, en consecuencia, la historiografía debe ser entendida como un arte (Kunstwerk) dedicado a las interpretaciones y no como una ciencia (Wissenschaft) preocupada por la representación fáctica del pasado" (Lemm, 2009, 471-482).

Es en este marco que Nietzsche provoca una refracción analítica en el problema de la animalidad moderna, resituando la animalidad del ser humano como una fuente artística y creadora de una nueva cultura. Este giro analítico, que saca al hombre de su relación mecanicista y evolucionista con la naturaleza, sitúa el olvido y la memoria como elementos constitutivos de una fuerza que permite al individuo interpretar creativamente el pasado. De esta manera, Nietzsche logra proponer una contra-historia que transformaría las contingencias pasadas en necesidades futuras, para concebir un pasado a partir del cual el hombre animal pueda proyectarse. Sería, entonces, la posibilidad concreta de desanclarse de la taxonomía ilustrada, a saber, aquella que posiciona al sujeto racional en la cumbre de la pirámide animal. Sólo volviendo al olvido animal del ser humano es posible la emergencia de un espacio para que el sujeto moderno devenga futuro, y no constitución -o reafirmación- de un pasado encarnado en un proyecto -teleológico- futuro.

En síntesis, tanto en Benjamin como en Nietzsche se evidencia el empeño por constituir un pensamiento que reduce a escombros el falso continuum de la historia oficialista, cuyo mayor logro estaría representado en la figura del ciudadano. Su trascendencia estaría entonces en la posibilidad reformular los soportes discursivos que sostienen el orden canónico de la ciudadanía moderna iluminista, entendida bajo el prisma del sujeto-de-gobierno dispuesto en la filosofía política kantiana, posibilitando una exploración distinta y generando vinculaciones ajenas a las realizadas por la historia de las continuidades, de las líneas de tiempo, de las memorias que nos guían hacia el origen único e indivisible del sujeto.

Como explica Foucault, se trataría, entonces, de escapar de las unidades y de las identidades que una cierta mirada histórico-filosófica plantearía como su analítica, exponiendo la artificialidad de la esencia y de su fundamento, mostrando cómo los grandes universalismos de nuestra cultura (conocimiento, derecho, sujeto) han sido el resultado de luchas de poder, deseos de dominación y prácticas de sometimiento (Foucault, 2004).

\section{BIBLIOGRAFÍA}

AGAMBEN, Giorgio. Lo Abierto. El hombre y el animal. Valencia, Editorial PreTextos, 2005 .

ALEGRÍA, Ciro. "De la justicia política al cosmopolitismo: un nuevo giro copernicano". En Derechos, Libertades, Emancipación. Cuadernos para el análisis. BERMUDO, José Miguel (Ed.). Barcelona, Editorial Horsori, 2010, pp. 179-206.

COHN, Priscilla. "Kant y el problema del derecho de los animales". Esplendor y Miseria de la Ética Kantiana. GUISÁN, Esperanza. (Ed.). Barcelona, Anthropos Editorial, 1998. pp. 197-213.

ESPOSITO, Roberto. Biopolítica y Filosofia. Buenos Aires, Amorrortu Editores, 2006.

Tercera persona. Política de la vida y filosofia de lo impersonal. Buenos Aires, Amorrortu Editores, 2009.

FOUCAULT, Michel. Tecnologías del Yo y otros textos afines. Barcelona, Ediciones Paidós Ibérica e I.C.E. de la Universidad Autónoma de Barcelona,1990. Nietzsche, la Genealogía, la Historia. España, Pre-Textos, 2004.

Obras esenciales. Madrid, Ediciones Paidós, 2010.

GALENDE, Federico. Walter Benjamin y la destrucción. Santiago de Chile, Ediciones Metales 
La ciudadanía como lo propriamente humano: digresiones entre la naturaleza indentitaria ilustrada...

Pesados, 2009.

HOBBES, Thomas. Leviatán. O la materia, forma y poder de una república eclesiástica civil. Argentina, Fondo de Cultura Económica, 2005.

KANT, Immanuel. Crítica De La Razón Pura. Nota, traducción, prólogo e índice, Pedro Ribas. Sexta edición. Madrid, Editorial Alfaguara, 1988.

¿Qué es la Ilustración? Y otros escritos de ética, política y filosofía de la historia. Madrid, Alianza Editorial, 2004.

La Metafísica de las Costumbres (1797). Madrid, Editorial Tecnos, 2005. Antropología en sentido pragmático. Buenos Aires, Editorial Losada, 2009.

KOJEVE, A. Introduction to the Reading of Hegel. Lectures on Phenomenology of Spirit. London, Cornell University Press, 1980.

PONCE, Antonio. "Moral sensitiva y moral racional: la Humanidad en Rousseau y Kant". Moral, derecho y política en Immanuel Kant. CARVAJAL, Julián (Ed.) Cuenca, España, Ediciones Universidad Castilla-La Mancha, 1999. pp. 117-143.

LANCEROS, Patxi. Avatares del hombre. El pensamiento de Michel Foucault. Bilbao, Universidad de Deusto, 1996.

. Política mente. De la revolución a la globalización. Barcelona, Anthropos Editorial, 2005.

LEMM, Vanessa. "Nietzsche y el olvido del animal". En ARBOR. Ciencia, Pensamiento y Cultura. CLXXXV 735 marzo-abril, 2009. pp. 471-482.

La filosofia animal de Nietzsche. Cultura, politica y animalidad del ser humano. Santiago de Chile, Ediciones Universidad Diego Portales, 2010a.

. "El umbral biológico de la política moderna: Nietzsche, Foucault y la cuestión de la vida animal". En LEMM, Vanessa (ed.). Michel Foucault: neoliberalismo y biopolítica. Santiago de Chile, Ediciones Universidad Diego Portales, 2010b, pp. 115-132.

NIETZSCHE, Friedrich. Estética y teoría de las artes, Madrid, Editorial Tecnos/Alianza, 2007.

PISARELLO, Gerardo. Un largo Termidor: historia y crítica del constitucionalismo antidemocrático. Quito, Corte Constitucional para el Periodo de Transición, Centro de Estudios de Difusión del Derecho Constitucional (CEDEC), 2012.

RUÍZ, Alfonso.: "El gobierno de ciudadanos libres e iguales", en: ARTETA, Aurelio. El saber del ciudadano. Las nociones capitales de la democracia, Alianza Editorial, Madrid, 2008, pp. 89-114.

SIPERMAN, Arnoldo. La ley moderna y el mundo moderno. Juristas, cientificos y una historia de la verdad. Buenos Aires, Editorial Biblos, 2008.

STOREY, Ian. "Kant's Dilemma and the Double Life of Citizenship". APSA 2011 Annual Meeting Paper, Washington DC, 2011, disponible en: http:///ssrn.com/abstract=1902443 (visitado 22 de septiembre de 2011).

\section{Notas}

1 En esta línea se puede intuir que, desde el momento en que el hombre firma el pacto de entrada al estado civil, posibilitado por su condición de sujeto autoconsciente y fundado en su condición inalienable de libertad en tanto hombre, no podría retornar a un estado precedente, frente al espacio de borradura de dicho lugar como categoría discursiva. En otras palabras, la naturaleza ilustrada operaría como momento de borradura de una naturaleza preconceptual, preontológica. Podríamos pensar que esta última constituye un espacio de exterioridad de primera, un archivo que, tal como nos señala Derrida, posee un principio anarchivistivo, a saber, de borradura de su propia huella: "No hay archivo sin lugar de consignación, sin una técnica de repetición y sin una cierta exterioridad. Ningún archivo sin afuera (...) El archivo trabaja siempre y a priori contra sí mismo" (Derrida, 1997, 19-20). Esta discusión nos retrotrae a la disputa entre la construcción del derecho político en Hobbes y Kant: si en el primero encontramos una referencia al estado de naturaleza como punto iniciático que ha de ser superado como forma de conservación de la vida, a partir de la renuncia voluntaria al estado de libertad amoral propio de este estado natural: “(...) el deseo de abandonar esa miserable condición de guerra que, tal como hemos manifestado, es consecuencia necesaria de las pasiones naturales de los hombres cuando no existe poder visible que los tenga a raya y los sujete" (Hobbes, 1992, 137), el caso es que en Kant dicho encuadre queda negado por el sólo hecho de que el hombre, en tanto que ser racional libre y autodeterminado, se encuentra guiado por una disposición natural hacia la comunidad: "La unión de muchos hombres en vista de algún fin (común, que todos tienen) se encuentra en todos los contratos sociales; pero la unión de esos mismos 
hombres, que es en sí misma un fin (que cada uno debe tener), por consiguiente la unión en toda relación externa de los hombres en general que no pueden menos que caer en influjo recíproco, es un deber incondicionado y primero: semejante unión no puede encontrarse si- no en una sociedad que se halle en estado civil, esto es, que constituya una comunidad" (Kant, 2004, 204-205). De este modo podríamos señalar que, de algún modo, en Kant la decisión de salida del estado de naturaleza ya ha sido tomada por una naturaleza sapientísima que, a su vez, se encuentra contenida en todos los hombres por el hecho de ser portadores de una subjetividad racional de orden práctico.

2 Al respecto, se puede pensar que la libertad para constituir un Estado para realizar un bien común es un derecho humano, ya que para ejercer las libertades políticas hay que tener asegurados los derechos fundamentales.

3 Es necesario precisar que la noción de «derechos humanos», entendidos como reconocimiento natural de los derechos del «género humano» ya se habría encontrado contenido en el llamado «derecho de gentes») del siglo XVI, particularmente en los desarrollos de la Escuela de Salamanca, particularmente bajo los postulados de Francisco Vitoria. Se podría pensar que esto constituye el antecedente del derecho natural ulterior.

4 Para Kant existe una relación inextricable entre la naturaleza y la razón, que se juega dentro de un continuo donado por la Naturaleza misma. Es por esto que no vemos un espacio de disputa sino una confianza en el desarrollo progresivo de la especie humana, considerando como foco un proceso de moralización orientado a la materialización histórica del Ideal de Humanidad. Esto queda refrendado en los primeros tres principios que propone el filósofo al referirse al desarrollo de su Historia Universal en clave cosmopolita (Kant, 2004, 99-102).

5 Kant se habría mostrado renuente a aceptar los principios eudemonistas y utilitaristas que situaban la felicidad como principio moral movilizador de nuestras acciones. En otras palabras, el filósofo nos quiere mostrar la imposibilidad de entender dicha finalidad -empírica- como un fin en sí mismo y, por ende, niega que ésta pueda ser objeto del imperativo categórico. Al referirse a la experiencia del mundo natural, la felicidad no sería más que un ideal de la imaginación sin determinación fija. En su lugar propondrá un «sentimiento moral», entendido como una exigencia inherente al hombre que, en su vertiente positiva, viene a representar la idea del respeto como ideal de la humanidad; y, en su vertiente negativa, constituye un sentido de exigencia que se personifica a través de una disposición del hombre a no dejarse guiar por las pasiones y los deseos propios de su condición orgánica.

6 Se hace necesario considerar que la introducción de la ciudadanía dividida en grados tiene su procedencia en el periodo siguiente a la Revolución Francesa. La figura del aristócrata disidente Emmanuel Sieyès se torna fundamental. Sieyès, representante del «Tercer Estado» francés, defendía la abolición de la desigualdad originada en los privilegios. Además, es él el primero en plantear la distinción entre ciudadanos «activos» y «pasivos»: "Todos los franceses son ciudadanos, pero hay ciudadanos activos, con plenos derechos políticos - un 15 por ciento de la población francesa- y ciudadanos pasivos, con menos capacidad e interés en la cosa pública (...) Y resultaba altamente funcional a un orden económico que pretendía basarse en el carácter sagrado del derecho de propiedad y de la libertad de industria" (Pisarello, 2012, 77)

7 El punto de unión entre el problema de la posesión y la condición de ciudadanía, se ve reflejado en el siguiente parágrafo de la Metafísica de las Costumbres, a propósito de la distinción entre posesión inteligible y posesión empírica y posesión inteligible. La primera es la que se da en el estado natural mientras que la segunda sólo se puede dar cuando se ha erigido una constitución civil: "Yo puedo llamar míos a una mujer, un niño, un siervo y, en general, cualquier otra persona, no porque yo los gobierne ahora como pertenecientes a mi casa, o los tenga bajo mi control, en mi potestad o posesión, sino, aunque se hayan sustraído a mi coerción y, por tanto, no los posea (empíricamente), si puedo decir, sin embargo, que los poseo por mi simple voluntad mientras existan en cualquier sitio y en cualquier momento, por tanto, de modo meramente jurídico; de ahí que pertenezcan a mi haber sólo si y en la medida que puedo afirmar lo último" (Kant, 2005, 59).

8 Respecto de este último punto debemos recordar que, para Kant, la imaginación impone la posibilidad que el conocimiento derivado de los objetos se vea afectado por la ilusión, decantando en la aparición de representaciones falsas, es decir, “(...) a las que no corresponde ningún objeto y en las que el engaño se debe unas veces a una ilusión de la fantasía (en los sueños) y otras, a un error del Juicio (en el llamado engaño de los sentidos)" (Kant, 1988, 349).

9 Para un tratamiento pormenorizado respecto al problema de los derechos animales, véase el texto de Cohn, P. (1998) titulado "Kant y el problema del derecho de los animales". 